\title{
Unilateral Periorbital and Cervical Subcutaneous Emphysema Following Extraperitoneal Laparoscopic Radical Prostatectomy
}

\author{
Jaydev Sarma*
}

Department of Anesthesia, Massachusetts General Hospital, 55 Fruit Street, Boston, MA 02114, USA

\begin{abstract}
A patient undergoing laparoscopic radical prostatectomy developed unilateral periorbital edema and cervical subcutaneous emphysema following carbon dioxide insufflation into the retropubic and retroperitoneal space. He had hypercarbia and acidosis during and after the end of the case and he required hyperventilation in the recovery room for two hours before the hypercarbia subsided and the arterial blood gases returned to normal levels. Despite massive surgical emphysema reaching up to his face, there was no evidence of a pneumothorax or pneumomediastinum in this patient. He had no respiratory distress and his visual examination was normal and the periorbital surgical emphysema subsided gradually within two days. The management of this complication and a review of the literature is presented.
\end{abstract}

Keywords: Subcutaneous emphysema, extraperitoneal laparoscopic prostatectomy.

\section{INTRODUCTION}

Subcutaneous emphysema following laparoscopic procedures is a well-recognized complication [1,2]. While carbon dioxide absorption is a problem associated with laparoscopic surgery in general, diffusion of carbon dioxide into the body is enhanced by certain procedural variables including the site of insufflation, the pressures of gas delivery systems, operative time, and increased patient age [1, 3, 4].

Laparoscopic radical prostatectomy (LRP) is theoretically a high-risk procedure for the development of hypercarbia and subcutaneous emphysema, reportedly occurring in $3.4 \%$ of patients [5]. Highlighted here is a case of a unilateral periorbital and cervical subcutaneous emphysema associated with hypercarbia and acidosis.

\section{CASE REPORT}

The patient was a 68 -year-old, ASA 2, male with a history of hypercholesterolemia, osteoarthritis of the knees, and adenocarcinoma of the prostate. He was $170 \mathrm{~cm}$ tall and weighed $85 \mathrm{~kg}$. Preoperative electrocardiogram showed normal sinus rhythm with a heart rate of 70 beats per minute. Vital signs and the physical exam were unremarkable. Anaesthesia was induced with propofol $2 \mathrm{mg} / \mathrm{kg}$, fentanyl 2 $\mathrm{mcg} / \mathrm{kg}$ and cisatracurium $0.15 \mathrm{mg} / \mathrm{kg}$ and the trachea was intubated easily with a $7.5 \mathrm{~mm}$ cuffed tracheal tube. Anaesthesia was maintained with $0.5-1 \%$ Isoflurane, $50 \%$ oxygen, $50 \%$ Nitrous oxide and a cisatracurium infusion at a rate of 4 $\mathrm{mgs} / \mathrm{hr}$. Volume controlled ventilation using $8 \mathrm{cc} / \mathrm{kg}$ tidal volume, with a PEEP (positive end expiratory pressure) of 5 $\mathrm{mmHg}$ and a rate of 8 breaths/minute was used. He also received $2 \mathrm{mg}$ of hydromorphone during the case.

The patient was positioned supine with 11 degrees of Trendelenburg tilt. Four laparoscopic trocars were placed in

*Address correspondence to this author at the Department of Anesthesia, Massachusetts General Hospital, 55 Fruit Street, Boston, MA 02114, USA; Tel: 508463 7918; Fax: 617566 0988; E-mail: jsarma@partners.org the retropubic space, left iliac fossa, and right iliac fossa to facilitate the surgical procedure. Carbon dioxide was insufflated to a pressure of $15 \mathrm{mmHg}$. Within two hours after the start of the operation the end-tidal carbon dioxide gradually increased from $40 \mathrm{mmHg}$ to $74 \mathrm{mmHg}$ in about fifteen minutes and the blood pressure rose from 130/80 to 170/94 $\mathrm{mmHg}$ and the patient's heart rate went up from 77 to 92 beats/min with a few premature ventricular contractions. Arterial blood gas revealed a pH 7.03, $\mathrm{PaO} 2274 \mathrm{mmHg}$, $\mathrm{PaCO} 2111 \mathrm{mmHg}$, and a bicarbonate of 27 . The respiratory rate and tidal volume was slowly increased to keep the endtidal carbon dioxide at around 40 to $45 \mathrm{mmHg}$. A maximum rate of 19 breaths per minute at $8 \mathrm{cc} / \mathrm{kg}$ tidal volume with a PEEP of $5 \mathrm{mmHg}$ was needed to keep the ETCO2 at 45 $\mathrm{mmHg}$. The total duration of the operation was 301 minutes.

Upon removal of the drapes at the end of the procedure, a marked left sided periorbital edema (Fig. 1) along with swelling of the neck and chest wall was seen. There was surgical crepitation on palpation of the tissues. A chest x- ray (Fig. 2) was taken and it did not show any pneumothorax or pneumomediastinum, even though gas bubbles were seen in the subcutaneous tissue. The tracheal tube was left in place and the lungs were electively hyperventilated with $50 \%$ oxygen in the recovery room and serial arterial blood gases were drawn. After two hours of hyperventilation the tracheal tube was removed once his arterial blood gases returned to normal levels and the subcutaneous emphysema had diminished considerably.

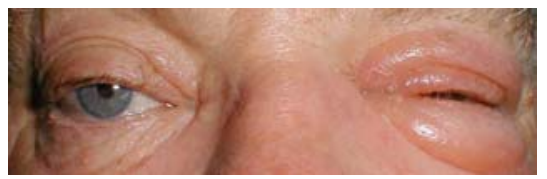

Fig. (1). Unilateral periorbital edema following insufflation of carbon dioxide during laparoscopic radical prostatectomy.

The patient was comfortable with stable vital signs, and he denied any chest pain or dyspnea. He reported no perior- 


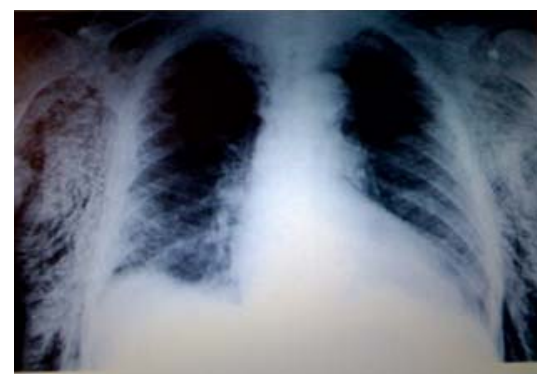

Fig. (2). Subcutaneous Emphysema following radical laparoscopic prostatectomy.

bital pain, pruritus, or change in vision. A full Opthalmic exam was done and no further diagnostic testing was advised. There was complete resolution of the periorbital subcutaneous emphysema by the following day.

\section{DISCUSSION}

Subcutaneous emphysema has been reported in association with laparoscopic and endoscopic procedures [6, 7]. Murdock et al. examined the independent predictors of hypercarbia (EtCO2 greater than $50 \mathrm{mmHg}$ ) and the development of subcutaneous emphysema in various laparoscopic surgeries. They reported the following: significantly increased risk with extra peritoneal laparoscopic procedures compared to intra peritoneal insufflation, age over 65 years, the use of six or more operative ports, and operative time over 200 minutes [1]. The presented case satisfies many of these parameters, namely an operative time of 301 minutes and the maximum recorded EtCO2 of $74 \mathrm{mmHg}$ and age of patient over 65 years.

Additionally significant in this case is the surgical site of insufflation. Access to the bladder neck and prostate in LRP is gained through the extra peritoneal retropubic space. Multiple studies have shown that carbon dioxide absorption is increased if insufflation is extra peritoneal versus intra peritoneal [3, 4, 8]. In a study evaluating patients undergoing laparoscopic total extra peritoneal hernioplasty, carbon dioxide absorption increased steadily during insufflation as well as throughout the duration of the surgery, as compared to a plateauing effect noted in the intra peritoneal group; median minute ventilation required for maintaining normocapnia was $12.9 \mathrm{~L} / \mathrm{min}$ for the extra peritoneal group, significantly larger than $9.5 \mathrm{~L} / \mathrm{min}$ required for the intra peritoneal group [4]. The minute ventilation in this case was increased throughout the operation, with a maximum respiratory rate of 19 breaths per minute and a minute ventilation over 13 litres. Interestingly, Sumpf et al. propose that intra peritoneal absorption of $\mathrm{CO} 2$ is limited at insufflation pressures above $14 \mathrm{mmHg}$ secondary to extrinsic compression of capillaries and subsequent reduction in capillary blood flow [4]. Such is not the case in extra peritoneal insufflation, where the resorptive surface area is increased with time, possibly augmented by the spread of gas along fascial planes during insufflation [4]. Of note, $100 \%$ of the patients in Sumpf's extra peritoneal hernioplasty group developed subcutaneous emphysema compared to $20 \%$ of the patients in the intra peritoneal group [4].

Singh et al. proposed another relevant operative risk factor for development of subcutaneous emphysema-leakage of carbon dioxide from trocar sites [9]. Specifically, all trocars pass through two tissue layers within the abdominal wall: the skin and muscle layer (or deeper fascial layer for extra peritoneal procedures such as laparoscopic radical prostatectomy). These two layers act as an inner and outer seal [9]. In more obese patients with thicker subcutaneous tissues, it is possible that the trocar cone does not reach the depth required to form a tight seal, resulting in leakage of carbon dioxide into the local subcutaneous tissue, and subsequently to more distal sites depending upon procedural duration, insufflation pressure, and subcutaneous tissue resistance [9].

Periorbital emphysema is most commonly observed due to disruption in the integrity of the orbital walls, most commonly through trauma with associated orbital or sinus fractures $[6,10]$. Periorbital and facial emphysema has also been associated with dental procedures and use of an air-andwater-cooled turbine burr drill [11]. Rarely, air progressing through the cervical fascia can extend along fascial planes to the face and periorbital region. Fortunately, periorbital emphysema subsides over the course of a few days without causing any visual disturbance [6]. Hyperventilation till carbon dioxide levels return to normal levels helps to reduce the periorbital emphysema.

Previous studies have demonstrated an anatomical connection between the cervical fascia and retroperitoneum [7]. Notably, the soft tissues of the neck are divided into three main compartments by layers of cervical fascia. Two of these three spaces terminate at the upper thoracic spine; the visceral space, however, descends further, investing the trachea and esophagus from the neck into the chest. Inferiorly, the visceral space extends with the esophagus through the diaphragmatic hiatus into the retroperitoneal soft tissues [7]. This pathway is elegantly displayed by a case report of spontaneous rupture of the esophagus (Boerhaave's Syndrome) manifesting as mediastinal emphysema with associated periorbital crepitation over the patient's left eye [10]. Laparoscopic radical prostatectomy, however, is an extra peritoneal procedure focused in the retropubic space. This space is known to be in direct communication with the retroperitoneum, clinically demonstrated by a case report highlighting retroperitoneal spread of a hematoma originating in the retropubic space [12]. Murdock notes an established link between preperitoneal insufflation and extensive dissection of retroperitoneal air [1].

There is a discrepancy to titrating ventilation to end-tidal carbon dioxide levels rather than arterial $\mathrm{CO} 2$. While studies have shown the peak end-tidal to arterial $\mathrm{CO} 2$ gradient to be 3-5 $\mathrm{mmHg}$, in the setting of increased alveolar dead space ventilation the gap widens and $\mathrm{EtCO} 2$ often underestimates arterial CO2 [13, 14]. Such an increase in alveolar dead space occurs in supine patients in nondependent regions where pulmonary arterial pressure falls below alveolar pressure and the capillaries are extrinsically compressed [15]. Therefore, direct arterial $\mathrm{PaCO} 2$ monitoring is recommended in patients with severe cardiorespiratory diseases because a normal EtCO2 achieved by increasing the minute volume can mask true hypercarbia and respiratory acidosis. Thus, the peak EtCO2 value $74 \mathrm{mmHg}$ in this case was an underestimate of the true arterial carbon dioxide tension of 111 $\mathrm{mmHg}$. 
The routine use of positive end expiratory pressure (PEEP) is controversial as hypotension is a rare but serious complication during $13 \%$ of laparoscopies [16]. It occurs mainly when the intra abdominal pressure exceeds $20 \mathrm{mmHg}$ due to compression of the inferior vena cava. Venous return from the lower half of the body is also impeded resulting in a reduced cardiac output particularly when PEEP is also applied. Mechanical ventilation with mild PEEP $(5 \mathrm{cms} \mathrm{H} 2 \mathrm{O})$ should be used. [16]. This improves arterial oxygenation intra operatively during laparoscopy without clinical cardiovascular compromise or respiratory complications.

Some anesthesiologists prefer not to use nitrous oxide due to the possibility of expansion of gas bubbles. Hypercarbia can cause the release of catecholamines leading to arrythmias due myocardial irritability. In this setting it would be advisable to hyperventilate with $100 \%$ oxygen and discontinuing nitrous oxide [17].

Extreme hypercarbia in the absence of hypoxia can affect EEG (electroencephalogram) and even cause flattening of the signal [18]. Should routine monitoring of the EEG or the BIS (Bi Spectral Index) monitoring become a standard of care for such cases and does a dip in the EEG signal call for the termination of the procedure as Yoshida et al. [18] indicate? We do not have answers for these questions yet.

The sudden rise in $\mathrm{EtCO} 2$ could also have resulted from an accidental insufflation of $\mathrm{CO} 2$ into the veins. However, if the $\mathrm{CO} 2$ embolism is large enough it would cause an obstruction of the pulmonary flow and reduce the cardiac output. This would, in turn reduce the $\mathrm{EtCO} 2$ and increase the arterial to end tidal PC02 difference and can sometimes be fatal [19]. Shulman et al. [20] however found the $\mathrm{EtCO} 2$ actually rose during embolization of $\mathrm{CO} 2$ gas.

Cephalad movement of the carina during laparoscopic procedures has been demonstrated by Morimura et al. [21] during intra peritoneal isufflation of carbon dioxide gas. The distended abdomen can push up the diaphragm and has the potential of causing an endobronchial intubation. Therefore it is important to monitor the position of the endotracheal tube during laparoscopic procedures, with a fiberoptic bronchoscope if necessary. Whether this can happen during extraperitoneal insufflation is not known.

As the popularity of laparoscopic extraperitoneal procedures grows, both anesthesiologists and surgeons should be aware of potential risks of hypercarbia and the cardiorespiratory complications that can occur (Table 1). Several variables probably increased the likelihood of this complication in this patient, including steep Trendelenburg position, extraperitoneal surgical approach, and prolonged operative time. Compensatory hyperventilation is impeded in steep Trendelenberg position and a high intra-abdominal pressure which causes a cephalad displacement of the diaphragm (resulting in reduction of lung volumes) and a restriction of diaphragm mobility can impede ventilation and worsen hypercarbia $[17,23]$. The presence of these complications necessitates the continuation of hyperventilation till the hypercarbia and respiratory acidosis is abolished [3, 17, 23, 25].

Gutt et al. [17] also point out that since the most used gas in laparoscopy is carbon dioxide, the correct terms to define its presence in pleural, mediastinal or pericardial cavities should be with capno rather than pneumo since a true pneumothorax is also possible as airway pressures can be higher than during an open procedure and can favor the rupture of a congenital bulla if present. It is important to make the distinction because capnothorax, capnomediastinum and capnopericardium rarely require intervention unlike a pneumothorax, pneumomediastinum or a pneumopericardium.

In conclusion, subcutaneous emphysema and hypercarbia occur frequently in patients undergoing extra-peritoneal insufflation of gases and is often of no great consequence [24]. The way to prevent or minimize this complication is to keep the dissection time below 200 minutes, slow insufflation, use of lower insufflation pressures (below $12 \mathrm{mmHg}$ ), good surgical techniques $[1,16]$ and constant monitoring for any surgical emphysema or periorbital edema. It should also be re-

Table 1. Cardio-Respiratory Complications Associated with Carbon Dioxide Insufflation for Extra-Peritoneal Laparoscopic Surgery

\begin{tabular}{|c|c|}
\hline Complication & Clinical Implication \\
\hline 1) Subcutaneous surgical emphysema & $\begin{array}{l}\text { May be associated with airway obstruction, pulmonary edema and atelectasis resulting in hypercarbia and } \\
\text { hypoxemia }[1,2,5-7,9,11,17,22-25]\end{array}$ \\
\hline 2) Periorbital edema & May or may not cause visual disturbance. Usually benign $[6,7]$ \\
\hline 3) pneumothorax (capnothorax) & $\begin{array}{l}\text { Capnothorax is usually benign, seldom requires chest tube placement if respiratory embarrassment is severe } \\
{[1,2,11,17,25]}\end{array}$ \\
\hline 4) pneumomediastinum (capnomediastinum) & $\begin{array}{l}\text { May cause cardio-respiratory changes due to impairment of compliance requiring high intrathoracic pressures } \\
\text { to ventilate the patient }[1,11,17,25]\end{array}$ \\
\hline 5) pneumopericardium (capnopericardium) & May affect filling pressures and consequently cardiac output $[17,25]$ \\
\hline 6) Carbon dioxide gas embolism & $\begin{array}{l}\text { Paradoxical embolism in patients with atrial septum defects, can affect cerebral oxygenation [17] } \\
\text { Fatal if large amounts of } \mathrm{CO} 2 \text { are injected intravascularly causing a gas lock in the right ventricle [19] }\end{array}$ \\
\hline $\begin{array}{l}\text { 7) Direct effects of insufflation-induced } \\
\text { hypercarbia }\end{array}$ & $\begin{array}{l}\text { Tachycardia, vasoconstriction, hypertension, increased myocardial irritability, arrhythmias (brady and tachy) } \\
{[1,2,5-9,11,17,19,22-25]}\end{array}$ \\
\hline 8) cardiac arrest & Due to gas embolism or vasovagal response $[17,19]$ \\
\hline 9) EEG (electroencephalogram signal) changes & Severe hypercarbia can cause flattening of the EEG tracing [18] \\
\hline
\end{tabular}


membered that in contrast to intra peritoneal insufflation, in which the carbon dioxide output falls upon cessation of insufflation, the carbon dioxide output remains high long after extra peritoneal insufflation has ceased and the patients should be monitored closely for a longer duration in the post operative period for any cardio-respiratory changes $[3,16,17,22-25]$ and positive pressure ventilation should be continued till normocarbia is established and signs of upper airway obstruction are absent.

\section{REFERENCES}

[1] Murdock CM, Wolff AJ, Van Geem T. Risk factors for hypercarbia, subcutaneous emphysema, pneumothorax, and pneumomediastinum during laparoscopy. Obstet Gynecol 2000; 95(5): 704-9.

[2] McAllister JD, D'Altorio RA, Snyder A. CT findings after uncomplicated percutaneous laparoscopic cholecystectomy. J Comput Assisted Tomography 1991; 15: 770-2.

[3] Streich B, Decailliot F, Perney C, Duvaldestin P. Increased carbon dioxide absorption during retroperitoneal laparoscopy. Br J Anaesth 2003; 91(6): 793-6.

[4] Sumpf E, Crozier TA, Ahrens D, et al. Carbon dioxide absorption during extraperitoneal and transperitoneal endoscopic hernioplasty. Anesth Analg 2000; 91: 589-95.

[5] Arai Y, Egawa S, Terachi T, et al. Morbidity of laparoscopic radical prostatectomy: summary of early multi-institutional experience in Japan. Int J Urol 2003; 10: 430-4.

[6] Aggarwal NK, Meyer D. Massive periorbital emphysema associated with laparoscopic nephrectomy. Ophthal Plast Reconstr Surg 2004; 20(5): 394-5.

[7] Colemont LJ, Pelckmans PA, Moorkens GH, et al. Unilateral periorbital emphysema: an unusual complication of endoscopic papillotomy. Gastrointest Endosc 1988; 34(6): 473-5.

[8] Mullett CE, Viale JP, Sagnard PE, et al. Pulmonary CO2 elimination during surgical procedures using intra- or extraperitoneal $\mathrm{CO} 2$ insufflation. Anesth Analg 1993; 76(3): 622-6.

[9] Singh K, Singhal A, Sagar VR, et al. Subcutaneous carbon dioxide emphysema following endoscopic extraperitoneal hernia repair: possible mechanisms. J Laparoendosc Adv Surg Tech 2004; 14(5): 317-20.

[10] Schneider SM, Goodman D. Spontaneous rupture of the esophagus presenting with unilateral proptosis. Ann Emerg Med 1984; 13(5): 374-7.
[11] Shackelford D, Casani JA. Diffuse subcutaneous emphysema, pneumomediastinum, and pneumothorax after dental extraction. Ann Emerg Med 1993; 22(2): 248-50.

[12] Boskovic V, Berisavac M, Petronijevic M, et al. Acute renal failure after cesarean section as a consequence of hematoma of the retropubic space of Retzius. Acta Chir Iugosl 2006; 53(1): 91-3. Serbian.

[13] Nunn JF, Hill DW. Respiratory dead space and arterial to end-tidal CO2 tension difference in anesthetized man. J Appl Physiol 1960; 15: 383-9.

[14] Takki S, Aromaa U, Kauste A. The validity and usefulness of the end-tidal pCO2 during anesthesia. Ann Clin Res 1972; 4: 278-84.

[15] West JB. Respiratory physiology: the essentials, $6^{\text {th }}$ ed, Philadelphia: Lippincott Williams and Wilkins, 2003, p. 37.

[16] Pang CK, Yap J, Chen PP. The effect of alveolar recruitment strategy on oxygenation during laparoscopic cholecystectomy. Anaesth Intensive Care 2003; 31: 176-80.

[17] Gutt CN, Oniu T, Mehrabi A, et al. Circulatory and respiratory complications of carbon dioxide insufflation. Dig Surg 2004; 21(2): 95-105.

[18] Yoshida H, Kushikata T, Kabara S, Takase H, Ishihara H, Hirota $\mathrm{K}$. Flat electroencephalogram caused by carbon dioxide pneumoperitoneum. Anesth Analg 2007; 105(6): 1749-52.

[19] Beck DH, McQuillan PJ. Fatal carbon dioxide embolism and severe haemorrhage during laparoscopic salpingectomy. Br J Anaesth 1994; 72: 243-5.

[20] Shulman D, Aronson HB. Capnography in the early diagnosis of carbon dioxide embolism during laparoscopy. Can Anaesth Society J 1984; 31: 455-9.

[21] Morimura N, Inoue K, Miwa T. Chest Roentgenogram demonstrates cephalad movement of the carina during laparoscopic cholecystectomy. Anesthesiology 1994; 81: 1301-2

[22] Myles PS. Bradyarrythmias and laparoscopy: A prospective study of heart rate changes with laparoscopy. Aust N Z J Obstet Gynaecol 1991; 31: 171-3.

[23] Koivusalo AM, Lindgren L. Effects of carbon dioxide pneumoperitioneum for laparoscopic cholecystectomy. Acta Anaesthesiol Scand 2000; 44: 834-841.

[24] Meninger D, Byhahn C, Wolfram M, Mierdl S, Kessler P, Westphal K. Prolonged intraperitoneal versus extraperitoneal insufflation of carbon dioxide in patients undergoing totally endoscopic robot-assisted radical prostatectomy. Surgical Endosc 2004; 18(5): 829-33.

[25] Khaitan A, Hemal AK. Complications of laparoscopic urology. Bombay Hosp J 2002; 44(2): 220-35. 